\title{
Expanding Growth and Pharyngeal Mass Formation in Elderly Patient With Esophageal Cancer: Unusual Manifestation
}

\author{
Takatsugu Yamamoto ${ }^{\mathrm{a}, \mathrm{b}}$, Koichiro Abe ${ }^{\mathrm{a}}$, Hajime Anjiki ${ }^{\mathrm{a}}$, Taro Ishii ${ }^{\mathrm{a}}$, Yasushi Kuyama ${ }^{\mathrm{a}}$
}

\begin{abstract}
Esophageal squamous cell carcinoma has invasive nature itself, and infiltration to the surrounding organs is common. We experienced a case of esophageal cancer with unusual manifestation. Eighty-oneyear-old female with 3 years history of cognitive disorder referred to our hospital because of dysphagia lasting for a month. The upper gastrointestinal endoscopy with thin scope revealed a whitecolored, soft mass lesion occupying almost whole of the lower pharynx. The lesion connected to the thickened esophageal wall, and the scope could not get through due to stenosis at the upper esophagus. The computed tomography showed marked thickness of the esophageal wall at the upper to middle portion without direct invasion or fistula formation to the surrounding organs. The lesion had protruding parts at the both edges, shown as low-density area on computed tomography, indicating inflammatory change. Pathological examination of the biopsied specimen showed squamous cell carcinoma of the esophagus and necrotic tissue of the pharynx. The patient initiated radiation therapy after tracheotomy was made, but died due to pneumonia two months later.
\end{abstract}

Keywords: Esophageal cancer; Expanding growth; Pharyngeal mass

Manuscript accepted for publication February 23, 2012

\footnotetext{
${ }^{\mathrm{a}}$ Department of Internal Medicine, Teikyo University School of Medicine, Tokyo, Japan

${ }^{\mathrm{b}}$ Corresponding author: Takatsugu Yamamoto, Department of Internal Medicine, Teikyo University School of Medicine, 2-11-1 Kaga, Itabashi-ku, 173-8605, Tokyo, Japan.

Email: ymmtmze@zpost.plala.or.jp
}

doi: $10.4021 / \mathrm{jmc} 587 \mathrm{w}$

\section{Introduction}

Esophageal squamous cell carcinoma has invasive nature itself, and infiltration to the surrounding organs such as bronchus is common. We report on a rare case of esophageal cancer with unusual manifestation.

\section{Case Report}

An 81-year-old female with 3 years history of cognitive disorder referred to our hospital because of dysphagia lasting for a month. The upper gastrointestinal endoscopy with thin scope revealed a white-colored, movable, soft mass lesion occupying almost whole of the lower pharynx (Fig. 1). The lesion connected to the thickened esophageal wall, and the scope could not get through due to stenosis at the upper esophagus (Fig. 2). The computed tomography showed marked thickness of the esophageal wall at the upper to middle portion.

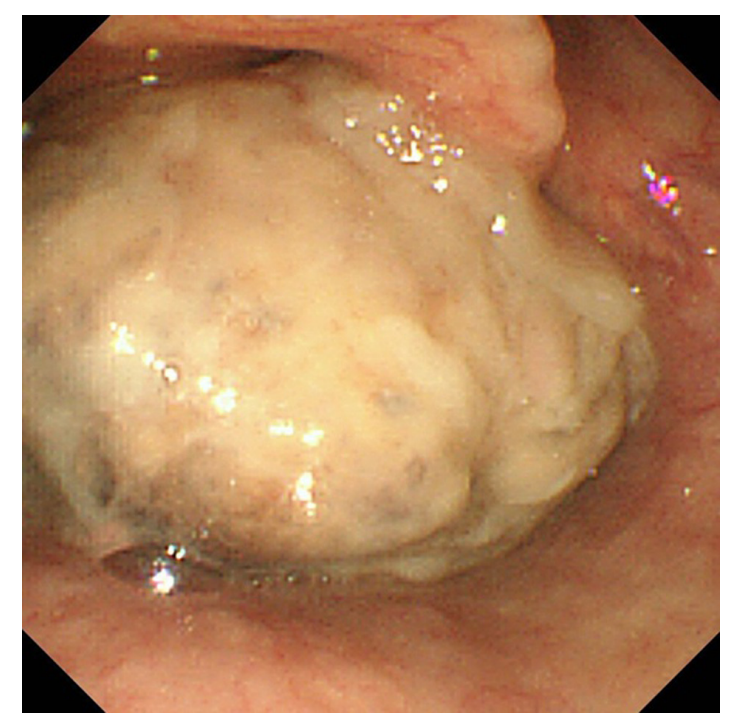

Figure 1. The upper gastrointestinal endoscopy with thin scope showed a white-colored, movable mass lesion occupying the lower pharynx. 


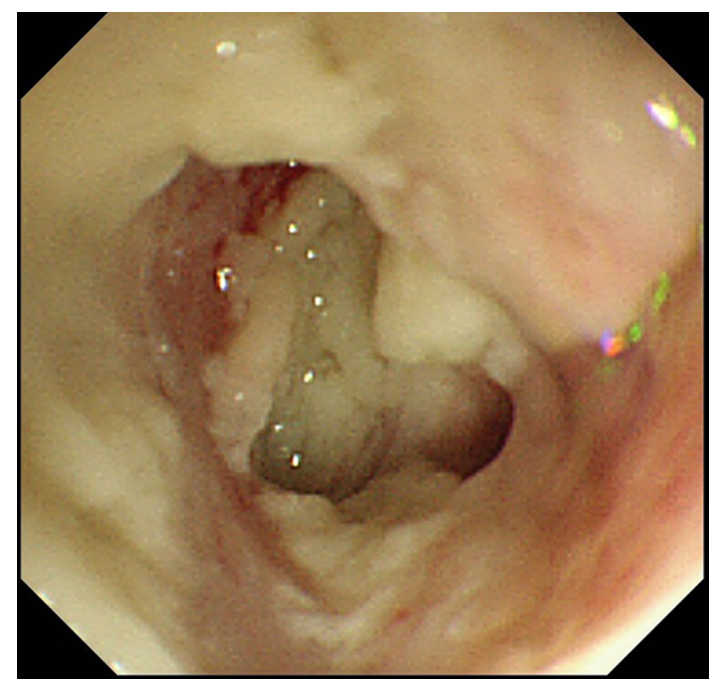

Figure 2. Stenosis was seen at the upper esophagus. The endoscope could not get through the stenosis.

The lesion had protruding parts at the both edges, shown as low-density area on computed tomography, indicating inflammatory change (Fig. 3-5). Pathological examination of the biopsied specimen showed squamous cell carcinoma of the esophagus and necrotic tissue of the pharynx (Fig. 6).

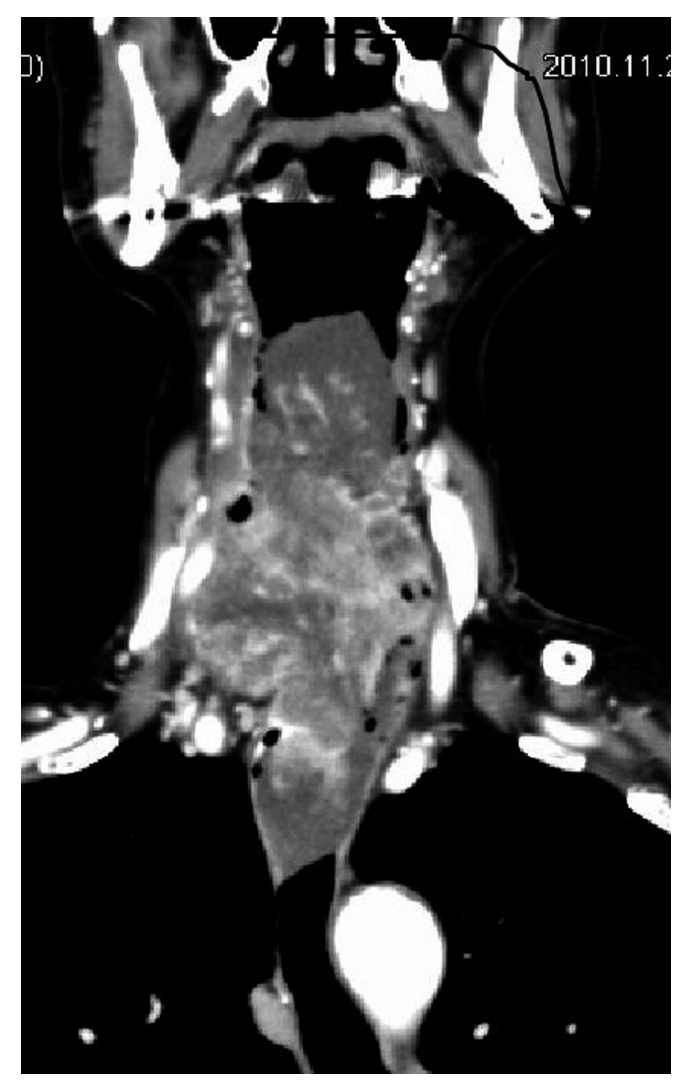

Figure 3. Computed tomography (frontal plane). A large mass occupied the lower pharynx.

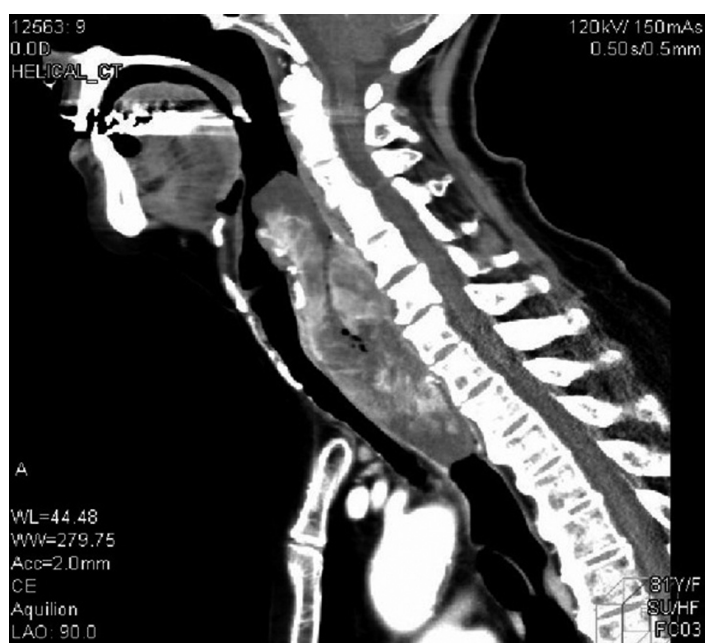

Figure 4. Computed tomography (sagittal plane). Marked wall thickness was seen at the upper to middle esophagus. The lesion had protruding parts at the both edges, shown as low-density area, indicating inflammatory change.

The patient initiated radiation therapy after tracheotomy was made, but died due to pneumonia two months later.

\section{Discussion}

More than $90 \%$ of esophageal malignancies are squamous cell carcinoma in Japan [1]. Esophageal squamous cell carcinoma is known its invasive nature, and invasion to the surrounding tissues including respiratory organs and mediastinum is common clinically [2]. The present case was rare at this point of view. As shown in Figure 3-5, the margin of the tumor to the other organs was clear, suggesting that

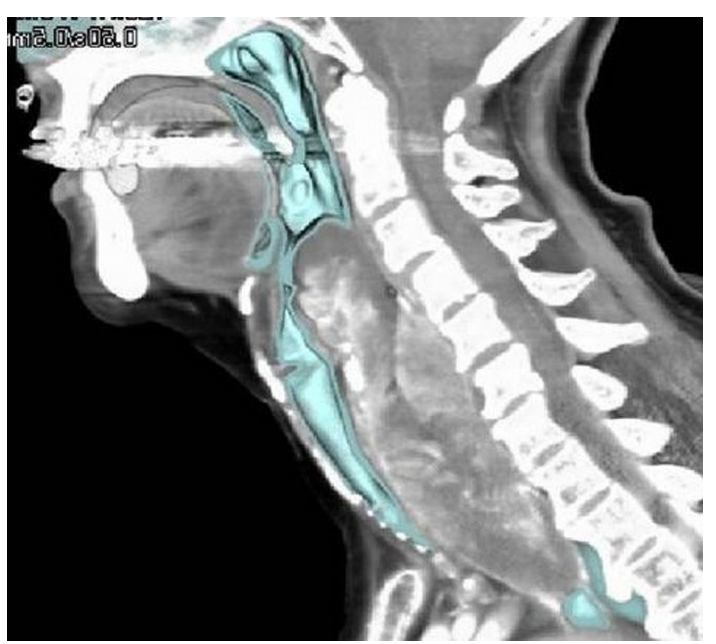

Figure 5. Computed tomography (sagittal plane with specific coloring). The border of the bronchus (showed as green area) looks clear and smooth. 


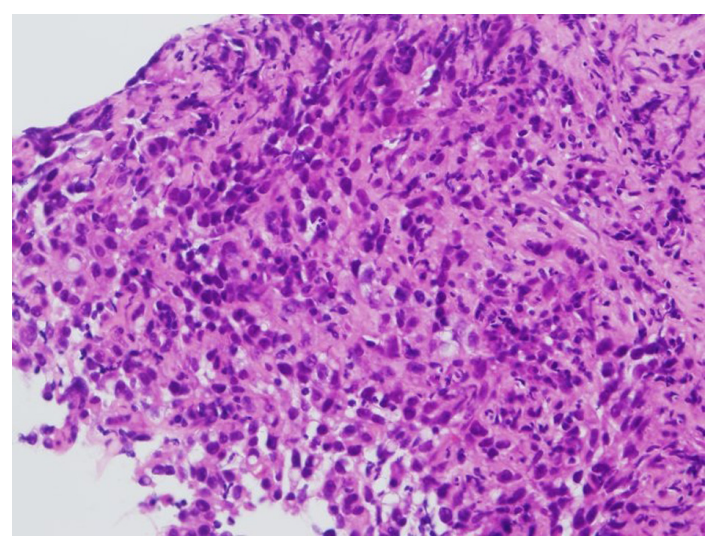

Figure 6. Pathological examination of the biopsied specimen showed squamous cell carcinoma of the esophagus (HE stain). the tumor grew not invasively but expansively. Additionally, it was also rare that esophageal cancer formed pharyngeal mass protruding from esophageal wall. Clinicians should know the variation of growing pattern of esophageal cancer.

\section{References}

1. Takubo K, Aida J, Sawabe M, Kurosumi M, Arima M, Fujishiro M, Arai T. Early squamous cell carcinoma of the oesophagus: the Japanese viewpoint. Histopathology. 2007;51(6):733-742.

2. Wolf MC, Stahl M, Krause BJ, Bonavina L, Bruns C, Belka C, Zehentmayr F. Curative treatment of oesophageal carcinoma: current options and future developments. Radiat Oncol. 2011;6:55. 